\title{
Differential aggregation of diatoms
}

\author{
Kenneth M. Crocker*, Uta Passow \\ Marine Sciences Institute, University of California, Santa Barbara, California 93106, USA
}

\begin{abstract}
The relative species composition of diatom flocs formed in the presence of 2 diatom species was studied in a series of laboratory experiments. The aim of this study was to investigate whether species composition in flocs reflected initial species composition or whether certain species were enriched in aggregates. In each experiment, 2 species with differing aggregation behavior were combined and aggregated. These experiments elucidate several mechanisms controlling aggregation of diatoms. Cells of Nitzschia angularis aggregated preferentially due to their high cell stickiness, which is a function of cell surface properties. Species such as Chaetoceros gracilis cause aggregation indirectly, by generating transparent exopolymer particles (TEP) which, in turn, scavenge cells into aggregates. Thalassiosira weissflogii did not form flocs itself, but was included in flocs formed by other species. Differential aggregation may lead to species succession during the bloom, and to sequential sedimentation. Flocculation behavior like that initiated by C. gracilis will most likely result in 1 mass sedimentation pulse, scouring of the water column and the end of the bloom.
\end{abstract}

KEY WORDS: Diatoms · Differential aggregation · Marine snow

\section{INTRODUCTION}

Marine diatom blooms are often terminated by aggregation and mass sedimentation of cells (Krank \& Milligan 1988, Alldredge \& Gotschalk 1989). Aggregation and subsequent sinking are hypothesized to be part of the life histories of many diatom species (Smetacek 1985, Logan \& Alldredge 1989). Speciesspecific sedimentation rates during diatom blooms may impact species succession (Smol \& Brown 1984) and have been attributed to differences in sinking velocities of single cells (Waite et al. 1992a), to differential dissolution of cells (Noji et al. 1986, Waite et al. 1992a) and to differential aggregation (Passow 1991). Field investigations revealed that composition of aggregates does not always mirror species composition of suspended plankton (Silver et al. 1978, Beeres et al. 1986, Revelante \& Gilmartin 1991, Riebesell 1991) and indicate that differential aggregation represents an important process leading to differential or sequential sedimentation.

- Present address: Ocean Sciences Centre, Memorial University of Newfoundland, St. John's, Newfoundland, Canada A1C 5 S7
Aggregation is described as a function of collision frequency and stickiness (Jackson 1990). The sticking coefficient $(\alpha)$ is defined as the probability that 2 particles will become attached upon collision. The sticking coefficients of diatoms are species specific and depend on their physiological state (Kiørboe et al. 1990, Logan et al. 1994). Collision frequencies depend on the motion of the water, as well as the sizes, shapes, sinking rates, and concentrations of cells. Sinking velocities of single cells, which influence collision frequencies between cells, are affected by nutrient and light availability (Culver \& Smith 1989, Waite et al. 1992b) and by cell size and shape (Smayda 1970). Speciesspecific aggregation may, therefore, be caused by morphological differences which influence collision frequencies and by physiological differences which influence both collision frequencies and stickiness.

Previous laboratory experiments and models have studied aggregation of diatoms in mono-specific systems (Jackson 1990, Kiørboe 1990, 1993, Passow \& Alldredge 1994). Our laboratory experiments investigated the formation of diatom flocs in the presence of 2 species to test 2 alternate hypotheses: Hypothesis $1-$ all cells present are scavenged into flocs, and relative species composition in aggregates mirrors abundance 
of cells; Hypothesis 2 - some diatoms aggregate preferentially while others are under-represented in flocs. Such differential aggregation may be the sole result of differences in collision frequencies due to differences in abundance and morphology of cells, or differences in the stickiness may contribute to differential aggregation. We furthermore hoped to understand the mechanisms responsible either for differential aggregation or for random passive scavenging of particles.

\section{METHODS}

Diatoms used for experiments. All diatoms were grown in batch cultures in $\mathrm{F} / 2$ with $\mathrm{Si}$ at $12^{\circ} \mathrm{C}$ and $100 \mu \mathrm{E} \mathrm{m}^{-2} \mathrm{~s}^{-1}$ light on a $12 \mathrm{~h}$ light: $12 \mathrm{~h}$ dark cycle. Three non-chain-forming diatoms, Nitzschia angularis, Thalassiosira weissflogii and Chaetoceros gracilis, were chosen based on their different flocculation characteristics.

The flocculation potential of Chaetoceros gracilis increases with culture age (Logan et al. 1994). During growth, cells of $C$. gracilis generate transparent exopolymer particles (TEP; Alldredge et al. 1993), which aggregate with $C$. gracilis cells forming a mucous matrix which incorporates cells (Passow et al. 1994). Nitzschia angularis aggregates easily during exponential phase and forms dense flocs which contain little polymeric material (Logan et al. 1994). If the culture is kept in early log phase for several days (by repeated dilution) flocculation of $N$. angularis may be retarded (see Expt 5). Thalassiosira weissflogii does not aggregate even during senescence (Logan et al. 1994).

Experimental set-up and sampling procedure. All experiments were conducted while cultures were in log or early stationary phase and began in the middle of the light cycle. Cells from 2 species, one floccing and one non-floccing, were combined in varying proportions (Table 1) in $285 \mathrm{ml}$ polycarbonate centrifuge bottles and the remaining space in each bottle was filled with filtered medium from both cultures. Bottles were rolled horizontally at $2 \mathrm{rpm}$ for up to $36 \mathrm{~h}$ on a roller table (modified from Shanks \& Edmondson 1989). Controls of each culture alone were rotated to confirm whether cells formed monospecific aggregates. Every 4 or $6 \mathrm{~h}$, the experimental bottles were checked for the presence of visible aggregates, and sampled if aggregates $1 \mathrm{~mm}$ or larger had appeared.

Aggregates were sampled by carefully removing and inverting a bottle, causing the aggregates to sink toward the bottle cap. When the majority of the aggregates present were near the cap, the bottle was righted and opened, allowing the slowly sinking aggregates to be captured with a needle and syringe. Aggregates were easily collected by this method, remaining aggre- gates were not disrupted and very little surrounding medium contaminated the sample, provided that care was taken during sampling. Due to the large size and density of the aggregates relative to the dilute medium, we are confident that sample contamination by surrounding medium was negligible. The volume lost by sampling $(<10 \mathrm{ml})$ was replaced with filtered culture medium. Sampled aggregates were diluted to $1 \mathrm{ml}$ with filtered seawater and buffered formalin and counted with a hemocytometer and compound microscope.

In Expt 1, Nitzschia angularis was combined with Thalassiosira weissflogii. Cell concentrations (Table 1) of each culture were chosen to set theoretical initial collision frequencies between cells of $T$. weissflogii equal to (Treatment 4) or larger than (Treatments 1 to 3) than collision frequencies between $T$. weissflogii and $N$. angularis or between cells of $N$. angularis.

In Expts 2 and 3, Chaetoceros gracilis were combined with Thalassiosira weissflogii. Initial cell con-

Table 1. Nitzschia angularis, Thalassiosira weissflogii and Chaetoceros gracilis. Initial cell concentrations $\left(10^{4}\right.$ cells $\left.\mathrm{ml}^{-1}\right)$ used for Expts 1 to 5. Initial concentrations for Expts 3 and 5 were calculated from stock culture concentrations, while Expts 1,2 and 4 are counts from samples taken at time zero

\begin{tabular}{|c|c|c|}
\hline \multirow{2}{*}{$\begin{array}{l}\text { Treatment } \\
\text { Expt } 1\end{array}$} & \multicolumn{2}{|c|}{ Cell concentration } \\
\hline & N. angularis & T. weissflogii \\
\hline 1 & 1.4 & 11.8 \\
\hline 2 & 0.5 & 9.9 \\
\hline 3 & 1.6 & 5.1 \\
\hline 4 & 3.0 & 1.6 \\
\hline Expt 2 & C. gracilis & T. weissflogii \\
\hline 5 & 48.3 & 2.1 \\
\hline 6 & 29.5 & 4.0 \\
\hline 7 & 27.5 & 3.5 \\
\hline 8 & 31.5 & 5.6 \\
\hline 9 & 6.2 & 4.0 \\
\hline Expt 3 & C. gracilis & T. weissflogii \\
\hline 10 & 47.0 & 1.2 \\
\hline 11 & 47.0 & 2.4 \\
\hline 12 & 47.0 & 4.7 \\
\hline 13 & 47.0 & 9.4 \\
\hline Expt 4 & C. gracilis & N. angularis \\
\hline 14 & 42.0 & 2.0 \\
\hline 15 & 39.7 & 0.7 \\
\hline 16 & 39.3 & 0.4 \\
\hline 17 & 39.5 & 0.2 \\
\hline Expt 5 & C. gracilis & N. angularis \\
\hline 18 & 46.2 & 1.9 \\
\hline 19 & 46.2 & 0.7 \\
\hline 20 & 46.2 & 0.4 \\
\hline 21 & 46.2 & 0.2 \\
\hline 22 & 11.6 & 4.8 \\
\hline 23 & 11.6 & 1.6 \\
\hline 24 & 11.6 & 0.5 \\
\hline
\end{tabular}


centrations were chosen to span all possible scenarios (Table 1): theoretical collision frequencies between $C$. gracilis were largest in the first treatment of each experiment and collisions between $T$. weissflogii were largest in the respective last treatments. In Expt 3 and subsequent experiments, special care was taken to keep the total amount of culture media (culture plus filtered culture) of each species constant between treatments. By keeping the total volume of the culture filtrate the same, we controlled for aggregation due to TEP present in filtrate while still varying cell numbers.

In Expts 4 and 5, Chaetoceros gracilis and Nitzschia angularis were combined. Both experiments were similar as far as cell concentrations of both species were concerned (Table 1). The culture of $N$. angularis used in Expt 4 was in its floccing phase, whereas the culture of C. gracilis used during this experiment was not floccing. Opposite flocculation behaviors were chosen for both species for Expt 5.

Preliminary experiments to ensure an even cell distribution within the bottles were conducted with a centrifuge bottle modified by the addition of a needle and septum through the cap. Thalassiosira weissflogii was rotated as described above and samples were withdrawn at specific locations near the top, bottom, center and sides of the rotating bottle and replaced with filtered medium through a second syringe. Cells were evenly distributed within the bottle for the first $20 \mathrm{~min}$ of the experiment, and continued to remain so after several hours.

Calculations of collision frequencies. Individual bottles rotating on their sides were used as aggregation chambers. After several minutes $(<10 \mathrm{~min})$, the liquid within a rotating cylinder achieves solid body rotation without shear (Lick et al. 1993, Jackson 1994). Thus collisions between particles in bottles are dominated by shear during the first phase of rotation (minutes) and by differential settlement during the latter phase (hours). Particles hitting container sides further complicate the system and an exact quantification of collision rates in rotating bottles is impossible (Jackson 1994). Nevertheless, we determined ratios at which to combine species for experiments by estimating initial collision frequencies based on shear and on differential settling (Eqs. 1 \& 2 below). Several ratios (different treatments) were chosen for each experiment to encompass a wide range of assumptions (see below). Calculations to predict species ratios expected within aggregates were based on the assumption of differential settling as the main mechanism of collision. We also calculated the respective predicted species ratios in aggregates based on maximal possible shear rates within the rotating cylinders (not presented). Predicted ratios based on these calculations were similar enough to those based on differential settling that the general conclusions drawn remained the same.

Collision frequencies for cells were calculated using Eqs. (1) \& (2) for shear and differential settling, respectively (McCave 1984, Jackson 1990):

$$
\begin{gathered}
C=G / 6\left(d_{i}+d_{j}\right)^{3} N_{i} N_{j} \\
C=\pi / 4\left(d_{i}+d_{j}\right)^{2}\left(W_{i}-W_{j}\right) N_{i} N_{j}
\end{gathered}
$$

where $C$ is the collision frequency $\left(\mathrm{s}^{-1} \mathrm{ml}^{-1}\right), G$ the local velocity gradient estimated at $0.209 \mathrm{~s}^{-1}$ from the rotation speed of bottles, $d$ the cell diameter $(\mu \mathrm{m}), W$ the sinking velocity $\left(\mathrm{cm} \mathrm{s}^{-1}\right)$ and $N$ the cell concentration $\left(\mathrm{ml}^{-1}\right)$. Subscripts $i$ and $j$ denote species $i$ and $j$, respectively.

The diameters $(d)$ of cells were approximated by equivalent spherical diameters (ESDs). Calculations of ESDs were complicated by the diverse shapes of the cells. Maximum and minimum ESDs were calculated for each species using lower and upper estimates of the volume swept clear by sinking cells (Fig. 1). Nitzschia angularis is a spindle-shaped diatom of approximately $44 \mu \mathrm{m}$ in length and $7 \mu \mathrm{m}$ in width, which may rotate while sinking. A minimum ESD of $N$. angularis was approximated from its equivalent spherical volume (Assumption N1). A maximum ESD was calculated from a sphere of a volume equivalent to the disk swept by the cells when rotated about their pervalvar axis (Assumption N2). N2 approximates the area of potential cell collisions for a diatom turning in 2 dimensions while sinking. A 3-dimensional approximation was rejected, as it would imply that a cell tumbled quickly enough to completely sweep out a sphere equivalent in diameter to the cell's length. Chaetoceros gracilis is disc-shaped (radius $=10 \mu \mathrm{m}$, height $=3.5 \mu \mathrm{m}$ ) with setae of approximately $50 \mu \mathrm{m}$. The ESD of C. gracilis was approximated by a sphere equivalent to the cell volume (Assumption C1) and by a sphere equivalent to the volume of the cell including setae in 2 dimensions (Assumption C2). The latter assumption allows for the possibility that cells may collide and attach on their extremities (Fig. 1). Thalassiosira weissflogii are cylindrical cells with an approximate width of $7.5 \mu \mathrm{m}$ and approximate length of $13 \mu \mathrm{m}$. T. weissflogii cells were approximated by spheres equivalent to their cell volumes (Assumption T).

Maximal and minimal sinking velocities were estimated from the size versus sinking velocity relation of Smayda (1970) using the maximal and minimal sizes of cells (Table 2). Predicted species ratios in aggregates (Table 3 ) were calculated using the above estimates of ESDs and assuming that all cells had the same stickiness. Averages of species ratios in flocs were compared to initial species ratios and to predicted species ratios. All values were converted to proportions and normal- 
Assumption C2

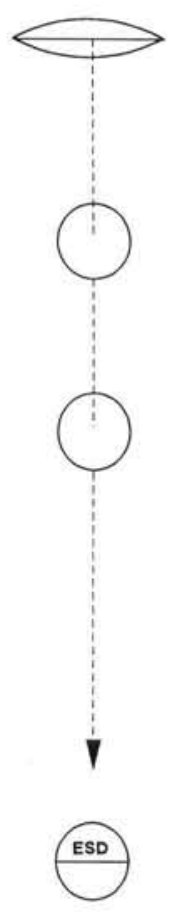

Cell Volume
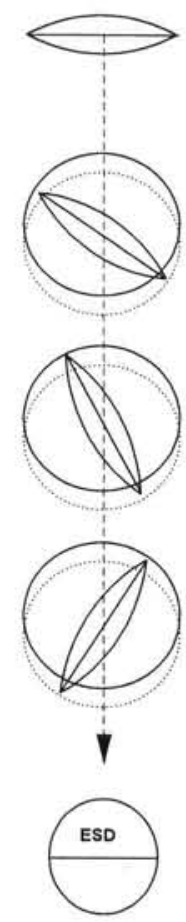

Volume of disk swept by cell
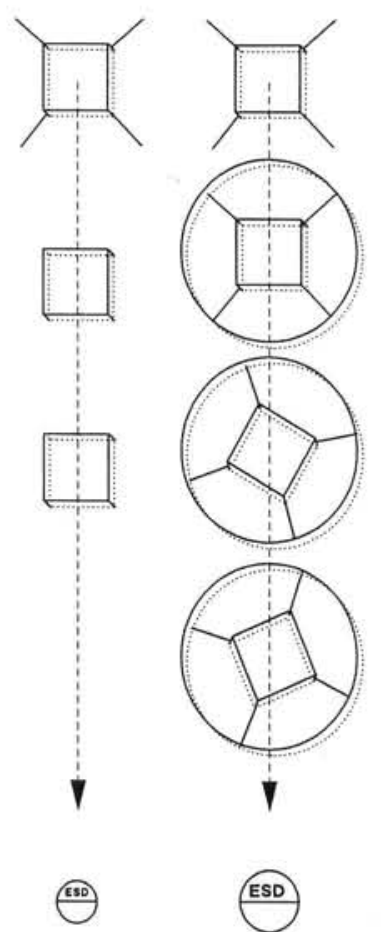

Cell Volume ized with the arcsine square root transformation for statistical analysis (Table 3). The calculations of theoretical aggregate compositions were developed to provide a yardstick against which to compare experimental results. Departures from predicted ratios simply mean that species composition in aggregates was not caused solely by differences in abundance and morphology of cells (different collision frequencies).

\section{RESULTS}

Expt 1 tested composition of aggregates formed by Nitzschia angularis and Thalassiosira weissflogii, when initial collision rates of $N$. angularis were similar (Treatment 4) or smaller (Treatments 1 to 3 ) than those between $T$. weissflogii. $N$. angularis formed dense aggregates in controls, but $T$. weissflogii did not aggregate in controls. Large aggregates were formed in all treatments combining $N$. angularis and $T$. weissflogii within $6 \mathrm{~h}$ of being placed on the rolling table. Aggregates in all treatments consisted of a higher proportion of $N$. angularis than was present in the initial mixtures and the proportion of $N$. angularis increased with time of rotation (Fig. 2). Average aggregate compositions as calculated in Table 3 do not reflect this increase in the fraction of $N$. angularis and the similarity between average floc composition and predicted floc composition in Treatment 1 is considered coincidental. Floc compositions did not reflect the compositions of the initial culture mixes, nor the aggregate ratios predicted from Eq. (2).

Expt 2 examined aggregates formed by Chaetoceros gracilis and Thalassiosira weissflogii at starting proportions spanning the whole range of initial collision frequencies. C. gracilis flocced in controls, but no aggregates were observed in controls of $T$. weissflogii. Large visible aggregates appeared within $12 \mathrm{~h}$ in treatments combining $C$. gracilis and $T$. weissflogii. These aggregates were loosely flocced and fragile. Species ratios in these aggregates showed no discernable pattern over time, but appeared to vary at random (Fig. 3). The average ratios of $C$. gracilis to T. weissflogii (statistically) matched predicted ratios in one treatment, but otherwise appeared to reflect initial concentrations best, except for Treatment 5 (see Table 3).

Expt 3 repeated Expt 2, but culture filtrate in different treatments was kept constant to correct for potential influence of TEP. As in Expt 2, flocs were formed in the control of Chaeto- 
Table 3. Nitzschia angularis, Thalassiosira weissflogii and Chaetoceros gracilis. Relative species composition in the initial suspension, in flocs, and predicted species concentration in flocs based on several assumptions. Predicted ratios give the ratios between both species expected in aggregates if all of the following assumptions apply: (1) collision rate was dominated by differential settling; (2) the stickiness of both species was the same; and (3) the respective Assumptions N1, N2, C1, C2 and T of ESD given in Fig. 1 apply. Note that for the 2 right-hand columns, N, T and C represent species names, not the assumption number. Experimental initial ratio reflects initial species composition in suspension. Mean experimental floc ratio represents the average ratio observed in aggregates during the experiment. ${ }^{*}$ A ratio which is within the confidence interval of the mean experimental floc ratio

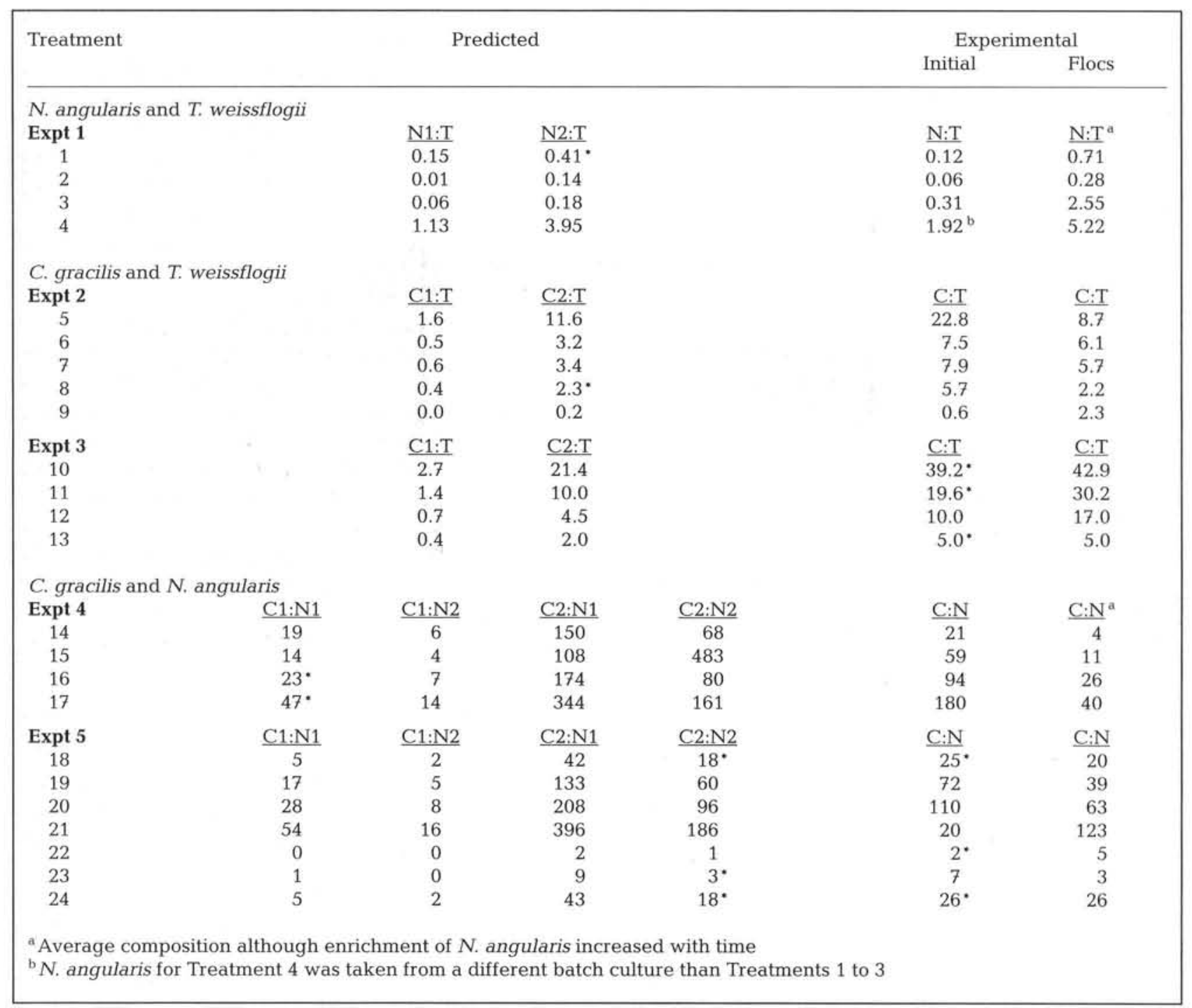

ceros gracilis, but not in that of Thalassiosira weissflogii. Large and fragile aggregates were formed within $15 \mathrm{~h}$ in treatments combining C. gracilis and T. weissflogii. As in Expt 2, the ratio of C. gracilis to $T$. weissflogii in aggregates varied greatly between samples and exhibited no trend with time (Fig. 4). Experimental C. gracilis to $T$. weissflogii ratios were statistically most similar to the initial ratios in 3 of the 4 treatments (Table 3 ).

Expt 4 investigated composition of flocs when nonfloccing Chaetoceros gracilis was combined with
Nitzschia angularis in floccing phase. C. gracilis did not aggregate in controls, while $N$. angularis formed compact aggregates within $24 \mathrm{~h}$. Large aggregates were formed within $24 \mathrm{~h}$ when $C$. gracilis and $N$. angularis were combined. As in the first experiment the contribution of $N$. angularis to aggregates increased with time of rotation (Fig. 5). Aggregates were disproportionately composed of $N$. angularis (Table 3 ) and did not reflect the composition of the initial culture mixes. The average composition in flocs statistically matched predicted composition in 2 treatments, but as 


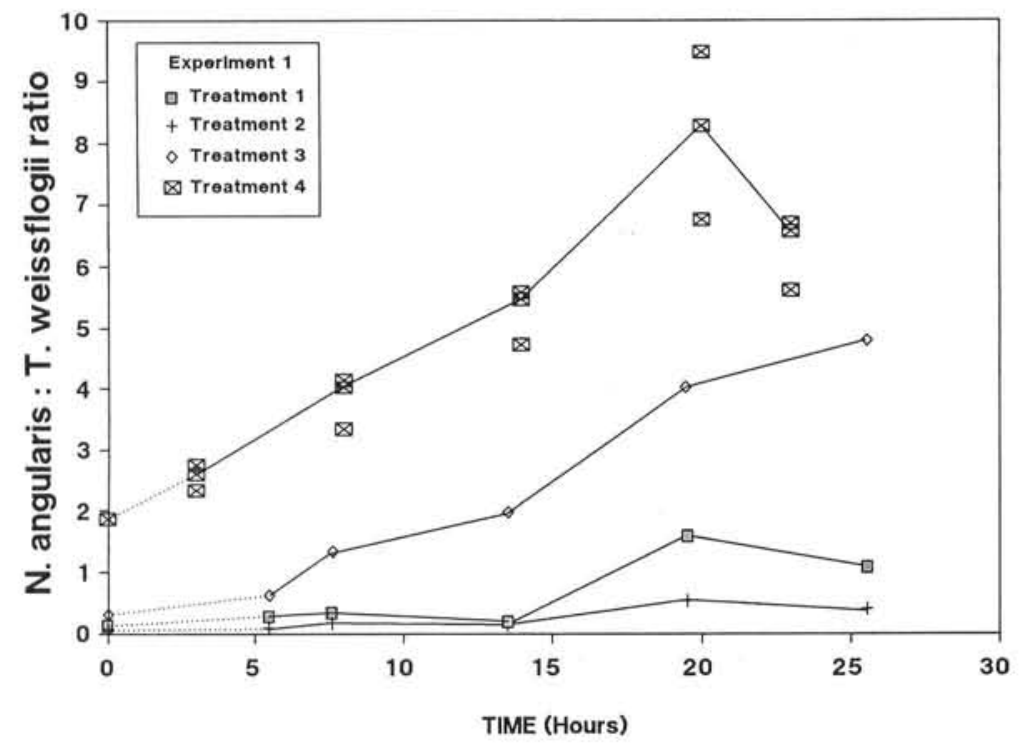

Fig. 2. Nitzschia angularis and Thalassiosira weissflogii. Changes in the ratios of $N$. angularis to $T$. weissflogii in aggregates during Expt 1 . This exweissflogii, when initial collision rates of $N$. angularis were similar to (Treatment 4) or smaller than (Treatments 1 to 3 ) those between $T$. weissflogii. Initial ratio of suspended cells is depicted at $t=0$ and connected to species ratios in aggregates by a dotted line periment tested composition of aggregates formed by $N$. angularis and $T$.

$N$. angularis were not floccing, $N$. angularis was not enriched. Chaetoceros gracilis was never enriched in flocs. Aggregates formed by $C$. gracilis reflected species composition of the suspended cells (Table 4).

In summary, no qualitative or quantitative differences were observed between treatments within each experiment, suggesting that differences in collision rates due to varying morphology and abundance of cells played a minor role in determining floc composition. The relative composition of aggregates formed during Expts 2 and 3 was also very similar, suggesting that the concentration of TEP did not limit aggregation due to TEP in any of the treatments of Expts 2 and 3. However, appearance and relative composition of flocs differed appreciably between the other experiments. The appearance of mixed flocs depended mostly on the species which initiated aggregation. When Nitzschia angularis was responsible for the aggregation, flocs were densely packed and resistant to disruption, similar to flocs formed by $N$.

in Expt 1, this similarity is not considered significant because of the increase of $N$. angularis in flocs with time.

Expt 5 examined aggregate composition when Chaetoceros gracilis in floccing phase was combined with non-floccing Nitzschia angularis. C. gracilis flocced within $12 \mathrm{~h}$ in controls, while no aggregates were formed in the control with $N$. angularis. Large visible aggregates appeared within $12 \mathrm{~h}$ when $C$. gracilis and $N$. angularis were combined. Aggregates were fluffy in appearance, similar to those formed in Expts 2 and 3. The species ratio of the aggregates varied over time without any discernable pattern (Fig. 6). Species composition in aggregates in 4 treatments were similar either to model predictions or to initial ratios and none of the species was enriched in flocs.

Average enrichment factors (EF) for the different species (ratio between the proportion of a species in an aggregate and its initial proportion in the suspension) are presented in Table 4. Nitzschia angularis was enriched in aggregates if it was in floccing phase. Consequently, the species with which $N$. angularis was combined was under-represented in these flocs. In Expt 5, where monocultures of angularis alone. $N$. angularis was enriched in these flocs and the proportion of $N$. angularis increased during rotation. When Chaetoceros gracilis was responsi-

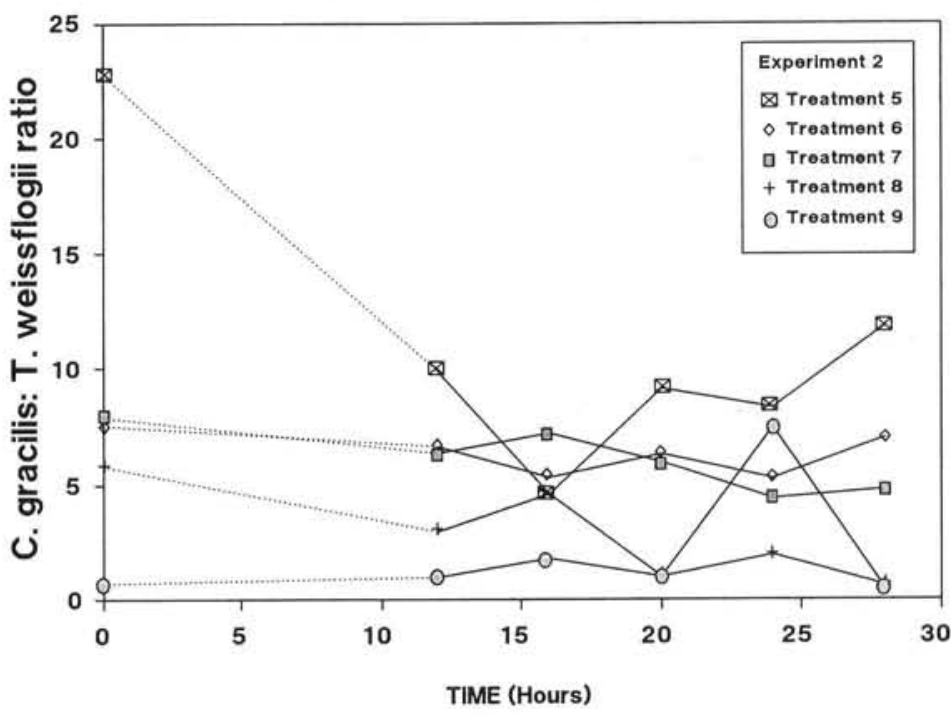

Fig. 3. Chaetoceros gracilis and Thalassiosira weissflogii. Changes in the ratios of $C$. gracilis to $T$. weissflogii in aggregates during Expt 2 . This experiment examined aggregates formed by $C$. gracilis and $T$. weissflogii at starting proportions spanning the whole range of initial collision frequencies. Initial ratio of suspended cells is depicted at $t=0$ and connected to species ratios in aggregates by a dotted line 


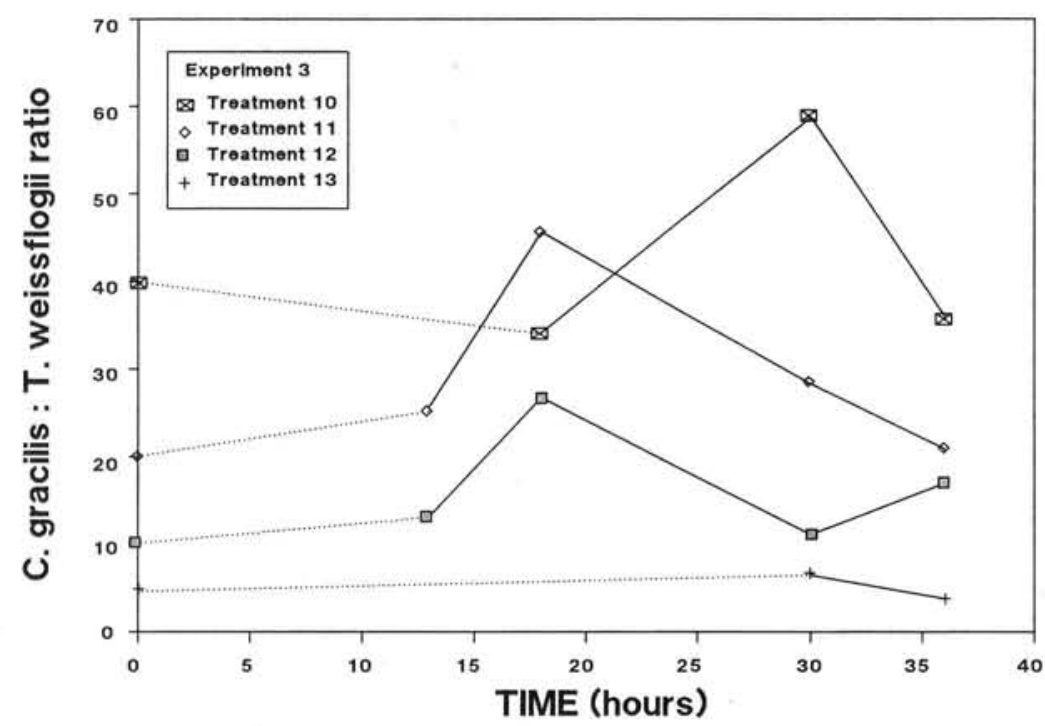

Fig. 4. Chaetoceros gracilis and Thalassiosira weissflogii. Changes in the ratios of $C$. gracilis to $T$. weissflogii in aggregates during Expt 3. This experiment repeated Expt 2, but culture filtrate in different treatments was kept constant to correct for potential influence of transparent exopolymer particles (TEP). Initial ratio of suspended cells is depicted at $t=0$ and connected to species ratios in aggregates by a dotted line

ble for aggregation, flocs appeared fluffy and were easily disrupted like monospecific flocs of $C$. gracilis. The composition of these flocs reflected roughly initial composition of cells and did not change with time. cells were low compared to the collision frequencies of the other species, indicating high sticking efficiency for collisions of $N$. angularis with itself compared to other collisions. A high $\alpha$ for collisions between $N$. angularis cells also explains why the relative contribution of $N$. angularis in flocs increased with time of rotation. The EF of $N$. angularis was similar between treatments, even though treatments covered a large range of relative concentrations, also indicating that $N$. angularis had a high $\alpha$. Estimates of relative collision frequencies, the relative increase of $N$. angularis in flocs and the small variability of the EF all suggest that the preferential aggregation of $N$. angularis was largely due to a greater stickiness of cells, rather than larger collision frequencies.

Aggregation of Chaetoceros gracilis follows a different mechanism. TEP are of primary importance for the aggregation of C. gracilis (Passow et al. 1994). TEP are formed from dissolved polysaccharides (Passow et al. 1994), which many diatoms excrete abundantly during growth (Myklestad 1974, Decho 1990). The stickiness of TEP is 3 to 4 orders of magnitude higher than that of C. gracilis cells and flocs are formed

\section{DISCUSSION}

The main question of this investigation was whether some diatom species became enriched in aggregates or whether species composition in aggregates reflected the composition of particles in suspension. Our results indicate that aggregates may be enriched in one species or they may mirror species composition in suspension depending on the specific aggregation behavior of the species aggregating.

Nitzschia angularis cells stick directly to each other when aggregating, which explains the dense appearance of flocs dominated by $N$. angularis (Passow \& Alldredge 1994). When $N$. angularis was in a floccing stage, its proportional contribution in mixed aggregates increased. Thus, this species flocs preferentially. $N$. angularis was enriched even in those treatments where the theoretical collision frequencies between $N$. angularis

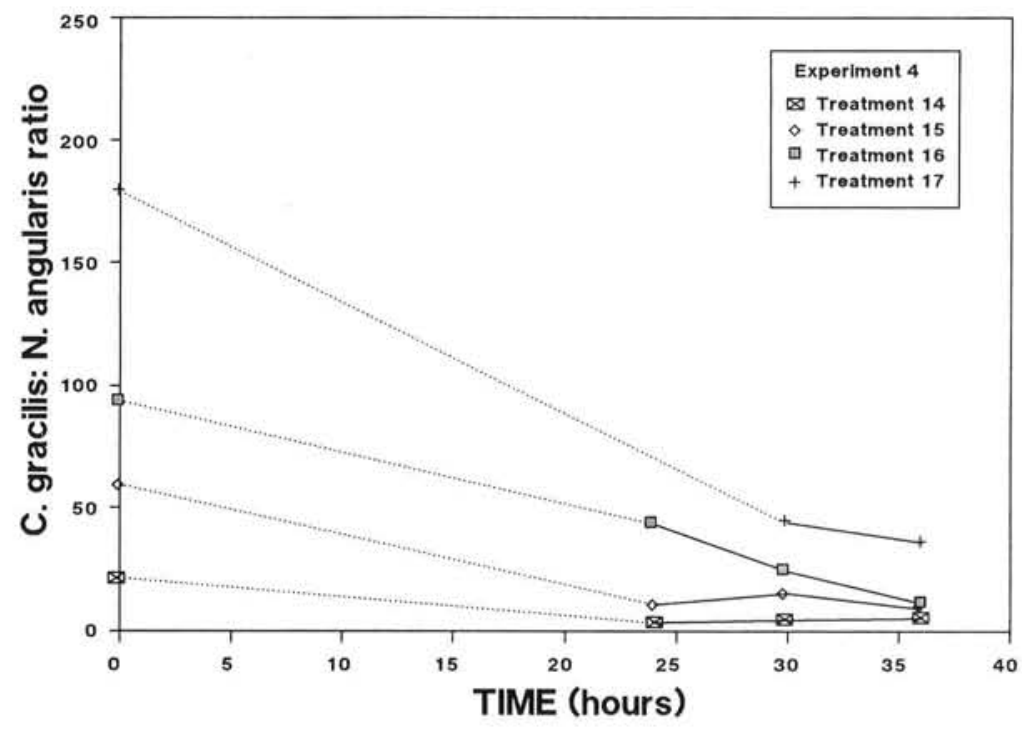

Fig. 5. Chaetoceros gracilis and Nitzschia angularis. Changes in the ratios of C. gracilis to $N$. angularis in aggregates during Expt 4. This experiment investigated composition of flocs when non-floccing C. gracilis was combined with $N$. angularis in floccing phase. Initial ratio of suspended cells is depicted at $t=0$ and connected to species ratios in aggregates by a dotted line 


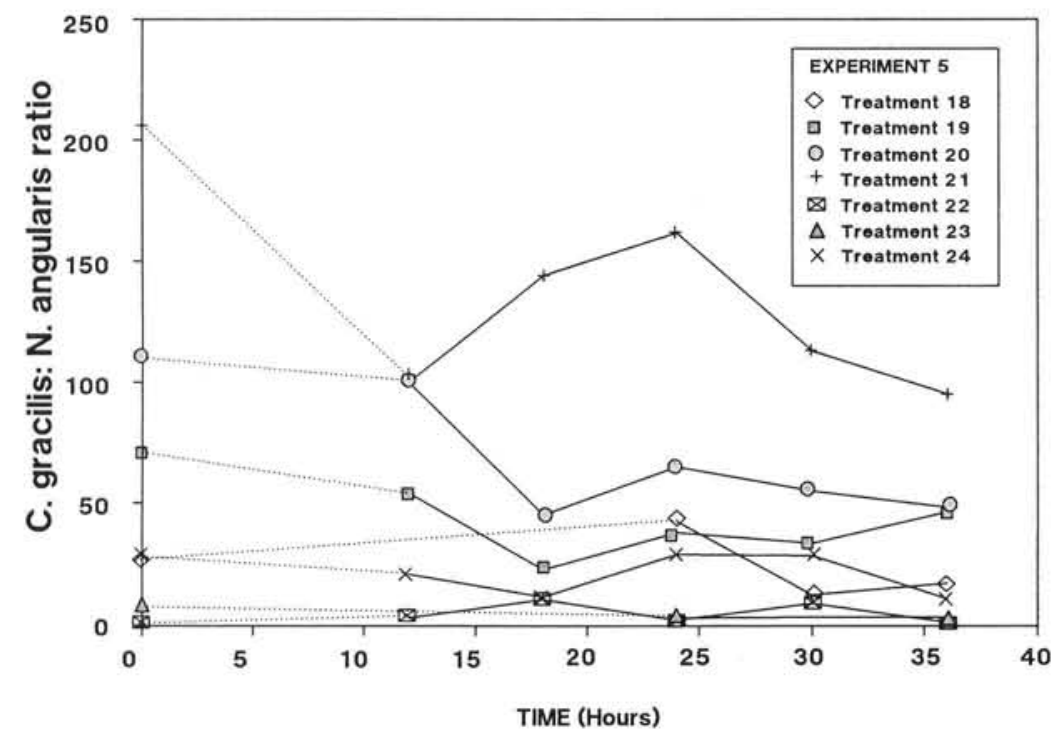

Fig. 6. Chaetoceros gracilis and Nitzschia angularis. Changes in the ratios of $C$. gracilis to $N$. angularis in aggregates during Expt 5. This experiment examined aggregate composition when $C$. gracilis in floccing phase was combined with non-floccing $N$. angularis. Initial ratio of suspended cells is depicted at $t=0$ and connected to species ratios in aggregates by a dotted line
Nitzschia angularis or Chaetoceros gracilis. The low contribution of $T$. weissflogii to flocs caused by $N$. angularis suggests that stickiness between $N$. angularis and $T$. weissflogii cells may have been low compared to stickiness of $N$. angularis with itself.

Measurements of stickiness coefficients confirm that the $\alpha$ of collisions between cells of Nitzschia angularis is higher than the $\alpha$ of collisions between Thalassiosira weissflogii cells (Logan et al. 1994). Sticking coefficients have generally been measured as the attachment efficiency between 2 cells of the same species (Kiørboe 1990, Logan et al. 1994). However, stickiness is not a characteristic of a particle type, but of a type of collision. Stickiness between 2 diatom species (interspecific) may not be directly inferred from the intraspecific stickiness of each species. Our data suggest 2 principally different mechanisms of attachment, which result in differences in interspe-

when TEP are abundant enough to incorporate cells in a mucous matrix (Passow et al. 1994). Flocs formed in treatments where $C$. gracilis was in floccing stage were loose and fluffy and contained large amounts of mucous material. They did not show a pattern of increasing enrichment with time. Flocs formed in the presence of floccing C. gracilis were never appreciably enriched in any species, suggesting that TEP scavenged all particles passively and randomly according to their proportion in the water.

Thalassiosira weissflogii never flocced in monoculture, indicating low stickiness of $T$. weissflogii with itself and the absence of sticky TEP. T. weissflogii was, however, found in flocs formed in the presence of

Table 4. Nitzschia angularis, Thalassiosira weissflogii and Chaetoceros gracilis. Average enrichment factors (EF) of species in flocs for Expts 1 to 5

\begin{tabular}{|cccc|}
\hline Expt & $N$. angularis & T. weissflogii & C. gracilis \\
\hline 1 & $3.1 \pm 1.1^{\mathrm{a}}$ & $0.6 \pm 0.2$ & - \\
2 & - & $1.7 \pm 0.6$ & $0.9 \pm 0.1$ \\
3 & - & $1.3 \pm 0.7$ & $1.0 \pm 0.0$ \\
4 & $4.3 \pm 0.5$ & - & $0.9 \pm 0.1$ \\
5 & $1.4 \pm 0.4$ & - & $1.0 \pm 0.1$ \\
& \\
a The average EF of Treatments 1 to 3 is $3.7 \pm 0.4$. N. angu- \\
laris from a different batch culture was used for Treat- \\
ment 4 and N. angularis may have been in a slightly \\
different flocculation phase \\
\hline
\end{tabular}
cific sticking behavior of particles with a high $\alpha$ for intraspecific collisions. Intraspecific stickiness of both N. angularis and TEP are high (Logan et al. 1994, Passow et al. 1994). However, TEP seems to behave more like glue, exhibiting a high stickiness towards most types of particles. Cell surfaces of $N$. angularis when cells are in floccing phase may behave more like Velcro ${ }^{\mathrm{TM}}$, sticking well only to specific counterparts.

Our results indicate that the species composition of a mixed diatom bloom in nature may determine the mechanism of aggregation and therefore the composition of aggregates. Sticky species, like Nitzschia angularis, will tend to aggregate and sink preferentially, leaving other species in suspension. For example, cells of Skeletonema costatum are sticky themselves, like $N$. angularis, and flocculation proceeds without the participation of TEP (Kiørboe \& Hansen 1993). S. costatum is consistently found to make a larger contribution to aggregates than surrounding seawater in coastal waters of California, USA (Crocker 1993). Species with lower $\alpha$ will not be included in such aggregates, but remain in the surface waters and continue to bloom. Differential aggregation during blooms may result in species succession during the bloom and sequential sedimentation.

If, on the other hand, a bloom is dominated by species like Chaetoceros gracilis, which generate TEP, other species present will also be entrained in aggrea large component of such species would tend to floc gates and removed from surface waters. A bloom with 
suddenly and completely, ending with 1 short sedimentation pulse. Thus, aggregate composition, bloom dynamics and flux to the benthos may all be significantly determined by the species composition of the bloom and the aggregation mechanisms of the species present.

Acknowledgements. The authors gratefully acknowledge the advice and support of A. Alldredge through all phases of these experiments. We thank A. Alldredge, S. Cooper, L. Dilling, C. Gotschalk, G. Jackson, W. Lick, B. Logan, G. Evans and 3 anonymous reviewers for comments and suggestions. This work was supported by ONR N0014-89-J-3206; U.P. was supported by the Deutsche Forschungsgemeinschaft, Pa 424/1-1.

\section{LITERATURE CITED}

Alldredge, A. L., Gotschalk, C. C. (1989). Direct observations of the mass flocculation of diatom blooms: characteristics, settling velocities and formation of diatom aggregates. Deep Sea Res. 36: 159-171

Alldredge, A. L., Passow, U., Logan, B. E. (1993). The abundance and significance of a class of large, transparent organic particles in the ocean. Deep Sea Res. 40: $1131-1140$

Beers, J. R., Trent, J. D., Reid, F. M. H., Shanks, A. L. (1986). Macroaggregates and their phytoplanktonic components in the Southern California Bight. J. Plankton Res. 8: 475-487

Crocker, K. (1993). Diatom aggregation and dimethylsulfide production in phytoplankton blooms. Ph.D. dissertation, Univ, of California, Santa Barbara

Culver, M. E., Smith, W. O. (1989). Effects of environmental variation on sinking rates of marine phytoplankton. J. Phycol. 25: 262-270

Decho, R. H. (1990). Microbial exopolymer secretions in ocean environments: their roles in food webs and marine processes. Oceanogr. mar. Biol. A. Rev. 28: 73-153

Jackson, G. A. (1990). A model of the formation of marine algal flocs by physical coagulation processes. Deep Sea Res. 37: 1197-1211

Jackson, G. A. (1994). Particle trajectories in a rotating cylinder: implications for aggregation incubations. Deep Sea Res, 41: 429-437

Kiørboe, T., Andersen, K. P., Damm, H. G. (1990). Coagulation efficiency and aggregate formation in marine phytoplankton. Mar. Biol. 107: 235-245

Kiørboe, T., Hansen, J. L. S. (1993). Phytoplankton aggregate formation: observations of patterns and mechanisms of cell sticking and the significance of exopolymer material. J. Plankton Res. 15: 993-1018

Krank, K., Milligan, T. G. (1988). Macroflocs from diatoms: in situ photography of particles in Bedford Basin, Nova

This article was submitted to the editor
Scotia. Mar. Ecol. Prog. Ser. 44: 183-189

Lick, W., Huang, H., Jepsen, R. (1993). The flocculation of fine-grained sediments due to differential settling. J. geophys. Res. 98: 10279-10288

Logan, B. E., Alldredge, A. L. (1989). Potential for increased nutrient uptake by flocculating diatoms. Mar. Biol. 101: 443-450

Logan, B. E., Passow, U., Alldredge A. L. (1994). Variable retention of diatoms on screens during size separations. Limnol. Oceanogr. 39: 390-395

McCave, I. N. (1984). Size spectra and aggregation of suspended particles in the deep ocean. Deep Sea Res. 31: $329-352$

Myklestad, S. (1974). Production of carbohydrates by marine planktonic diatoms. I. Comparison of nine different species in culture. J. exp. mar. Biol. Ecol, 15: 261-274

Noji, T., Passow, U., Smetacek, V. (1986). Interaction between pelagial and benthal during autumn in Kiel Bight: development and sedimentation of phytoplankton blooms. Ophelia 26: 333-349

Passow, U. (1991). Species-specific sedimentation and sinking velocities of diatoms. Mar. Biol. 108: 449-455

Passow, U., Alldredge, A. L. (1994). Distribution, size and bacterial colonization of transparent exopolymer particles (TEP) in the ocean. Mar. Ecol. Prog. Ser. 113: 185-198

Passow, U., Logan, B. E., Alldredge, A. L. (1994). The role of particulate carbohydrate exudates in the flocculation of diatom blooms. Deep Sea Res. 41: 335-357

Revelante, N., Gilmartin, M. (1991). The phytoplankton composition and population enrichment in gelatinous 'macroaggregates' in the northern Adriatic during the summer of 1989. J. exp. mar. Biol. Ecol. 146: 217-233

Riebesell, U. (1991). Particle aggregation during a diatom bloom. Biological aspects. Mar. Ecol. Prog. Ser. 60: 281-291

Shanks, A. L., Edmondson, E. W. (1989). Laboratory-made artificial marine snow: a biological model of the real thing. Mar. Biol. 101: 463-470

Silver, M. W., Shanks, A. L., Trent, J. D. (1978). Marine snow: microplankton habitat and source of small-scale patchiness in pelagic populations. Science 201: 371-373

Smayda, T. J. (1970). The suspension and sinking of phytoplankton in the sea. Oceanogr. mar. Biol. A. Rev. 8: 353-414

Smetacek, V. S. (1985). Role of sinking in diatom life-history cycles: ecological, evolutionary and geological significance. Mar. Biol. 84: 239-251

Smol, J. P., Brown, S. R. (1984). A hypothetical relationship between differential algal sedimentation and diatom succession. Verh. int. Verein. Limnol. 22: 1361-1365

Waite, A. M., Bienfang, P. K., Harrison, P. J. (1992a). Spring bloom sedimentation in a subartic ecosystem. II. Succession and sedimentation. Mar. Biol. 114: 131-138

Waite, A. M., Thompson, P. A., Harrison, P. J. (1992b). Does energy control the sinking rate of marine diatoms? Limnol. Oceanogr. 37(3): 468-477

Manuscript first received: November 22, 1993 Revised version accepted: August 16, 1994 